\title{
Teachers' experiences of student feedback: A view from a department of social work in Sweden
}

Michael Wallengren Lynch, University of Malmö, Sweden

\begin{abstract}
INTRODUCTION: Course evaluations play a significant part in the facilitating of educational programmes at a university. Along with course evaluations, students are often asked for their reflections on teachers' pedagogical methods and approaches. These types of questions can be referred to as student evaluations of teaching, or SETs. Separately, there is growing, yet underdeveloped, interest in understanding the emotional impact the role of being a university lecturer has on the individual teacher. This piece of work is interested in combining the areas of teacher development, SET and emotional impact. Therefore, this research is seeking to understand how teachers in a department of social work engage with student feedback, manage this feedback and understand pedagogical self-development.
\end{abstract}

METHODS: A mixed approach (an online survey and semi-structured interviews), was taken to gather the experiences of the teachers.

FINDINGS: The results show that all the teachers engaged with student feedback. It also showed that some teachers experienced negative emotions regarding feedback that were unpleasant but had strategies to deal with the feedback.

CONCLUSION: The results also pointed towards individual-directed solutions as the drivers behind creating good practices around pedagogical self-development, and for managing any emotional impact of SETs.

KEYWORDS: emotional impact; student evaluation of teaching; individual strategies
Student evaluations are a common part of the student and teaching experiences at universities, despite the issues long identified with their validity and reliability (Wolfer \& McNown Johnson, 2003). Since the 1970s, student evaluations have a played significant part in the running of educational programmes at a university (Kogan, Schoenfeld-Tacher, \& Hellyer, 2010). Universities have tried many different approaches to gathering evaluations from students, such as group meetings and regular meetings with class representatives. Efforts to offer feedback on teachers' own pedagogical development have, however, not been so flexible or creative. Indeed, students' feedback tends to remain the most widely used method of feedback on teaching (Johnson \& Wolfer, 2001). Furthermore, the teaching evaluation is often mixed in with evaluations on the administration of courses and, in the view of Johnson and Wolfer (2001), is not optimally designed for supporting teachers with their pedagogical
AOTEAROA

NEW ZEALAND SOCIAL WORK 31(2), 57-63.

CORRESPONDENCE TO: Michael Wallengren Lynch michael.wallengren-lynch@ mau.se 
development. This paper takes the analysis one step further in the direction of the impact the actual student feedback has on teachers, be it experienced as positive or negative. Therefore, the aim of this study is to give a space for teachers to express their experiences of anonymous feedback on their teaching. As a result, the following questions will be the focus of the paper:

- Do teachers read and identify with student feedback?

- How do the teachers process the feedback on professional and personal levels?

- What strategies do teachers use for pedagogical self-development?

\section{Background and rationale for research}

The context of student feedback in current times must be considered in reference to dominant discourses around education and students as consumers of their education. At the forefront of these discourses is New Public Management (NPM), which has been a defining characteristic of contemporary university teaching across Europe over the last 20 years. This business-based approach to the management and delivery of education has had significant impact on how a university is run. This has resulted in a move "from more collegial and horizontal accountability to more vertical reported through new layers of performance indicators and performance management systems, along with growing activities of regulatory bodies..." (de Lourdes Machado, Soares, \& Teichler, 2017, p. 236). NPM has also created the rhetoric of students as consumers and "coupled with a faith in the power of the markets to have their needs met" (p. 236). As a consequence, comments from students can be seen from the perspective of a satisfied or dissatisfied customer (Budd, 2017). These comments can have a significant impact on careers in some countries, such as the USA (Kogan et al., 2010), when applying for tenure or in wage negotiations. This approach to public affairs also refers to increased competition, budgetary constraints, reforms based on performance, assessment and monitoring and increasingly managerial roles taken on by academics. The aforementioned idea of the students as consumers of their education also feeds into this rhetoric. The practice of social work is also privy to NPM language contests. For instance, in the United Kingdom, criticism has been levelled against government spin which uses the language of social work (use of empowerment, for example) but often in a tokenistic and superficial manner (Heffernan, 2005).

Much has been written about the impact NPM has had on the practice of workers and its impact for clients/service users in the public service, but the impact of NPM practices on the individual teacher in the university setting is seldom explored. Their emotional well-being is seldom looked at when compared to teachers in other educational settings such as primary and secondary schools. A useful concept to help focus the discussion is Soini, Pyhältö, \& Pietarinen's (2010) idea of "pedagogical well-being". They argue that teachers in secondary school settings can experience "the pedagogical processes within school communities [through] either feelings of engagement and empowerment and a sense of satisfaction or feelings of stress and anxiety" (p. 736). The teacher can experience stress through dealings with parents and joy and empowerment through their interaction with students. They argue that how one experiences pedagogical wellbeing can have an impact on a teacher's self-image and self-esteem. Many factors make up pedagogical well-being and it is the contention of this paper that feedback from students plays its part. Seeking to explore the interplay between the "audit society" (Power, 1999), where everything is "measurable and held accountable", and the practices of the university teacher are relevant to help us understand the emotional engagement NPM policies and 
practices can have on individuals and to develop a sense of teachers' pedagogical well-being. The emotional impact felt by the teacher in universities is complex, contextbased and is not solely centred on student expectations and feedback. Studies show that organisational factors, job dissatisfaction, burnout and health symptoms are all linked to high levels of emotional labour in teaching (Schutz \& Zembylas, 2009). However, given that student-teacher interactions are the most prevalent source of teacher emotions in their role (for a review, see Sutton \& Wheatley, 2003), there is a strong case for seeking to understand this relationship. In addition, Quinlan (2016) writing on higher education teaching and learning underpins the importance of relationships for emotions in interactions and vice versa, which stresses the need for more empirical research on that issue. Often the university lecturer's path is solitary, especially when it comes to teaching development and managing stress. There is considerable research on teachers' stress and working conditions in other educational stages, such as secondary school (see for example, Kyriacou (2001)), but understanding the emotional impact of working as a university lecturer is still largely in its infancy. The university teacher is expected to entertain, inspire, motivate, explain and examine. In the everyday teaching setting the role is performance-based and played out in front of live audiences with SETs as the voice of the critic. This requires extensive emotional management on behalf of the teacher in order to "induce or suppress feeling in order to sustain the outward countenance that produces the proper state of mind in others" (Hochschild, 1983, p. 7). Hence emotional labour involves the "management of feeling to create a publicly observable facial and bodily display and it is instrumental in that it involves the management of feeling ... for the benefit of another person" $(1983$, p. 7). The ideas of pedagogical well-being and emotional well-being are interlinked and the research questions in this paper seek to understand how this is played out in the respondents' everyday teaching.
It is important to note that this paper considers that dialogue with students is crucial to the development of teaching of social work and gaining constructive alignment. Constructive alignment (Biggs, 1999,2003 ) is based on the theory of constructivism and states that the teacher should align the planned learning activities with the learning outcomes. Many researchers in social work education grapple with the challenge of teaching theories and approaches that students are expected to integrate into their future practice. These theories often ask the students to reflect critically on their future roles as social workers but, at times, "educators are rarely held to this same standard" (Teater, 2011, p. 572). The pedagogical practices of aiming for constructive alignment can be seen in parallel to the influence NPM has had on the approaches to managing education and how the language of Briggs is adapted to serve the interests of NPM approaches. For example, the need for feedback strategies is key to a constructive alignment approach (Teater, 2011); however, the majority of these approaches seldom refer to feedback on the teachers' actual teaching. Instead, generally, feedback refers to students' learning and feedback as consumers of their education.

\section{A critical take on SET}

Much of the published research takes a critical stance on student feedback and on SETs. There have been many questions over the last 20 years regarding the relevance of SET (Hornstein, 2017), in particular countries (e.g., USA) where SETs are used as arguments for tenure appointments and in salary negotiations. In the author's experience, SETs in Sweden tend to be used for discussions about course improvement amongst course teachers and are not necessarily part of wages or professional development conversations with line managers. However, this is not to say that this is the case for other social work academics working in Swedish universities. Many studies problematise students' methods of evaluation as the criteria that 
students use are likely to be unrelated to teachers' actual teaching qualities (Boring, 2015). On top of this, response rates tend to be around the $29 \%$ mark, bringing the reliability of using student assessment as a fair measure of a teachers' pedagogy into question. Braga, Paccagnella, and Pellizzari (2014, p. 85 point out that "good teachers are those who require their students to exert effort and students dislike having to expend this effort, especially the least able ones, and their evaluations reflect the utility they enjoy from the course". Research has also found that, by looking at SETs from the students' perspective, younger people are more likely to give criticism, show a gender bias in their responses and "punish" their teachers through the SET. The format of teaching, the size of the classroom and even the subject matter have also been shown to play a role in students' responses. Hamermesh and Parker (2003) identified that physical attractiveness can also impact SETs. Sebastian and Bristow (2008) found that students rated female teachers dressed in formal clothes as less likeable when compared to female instructors in casual dress. Style of dress in this study did not, however, impact likeability for male instructors. In defence of the student position, it has also been suggested that students are not guided as to what constitutes good teaching and therefore their feedback can be based on emotional reactions and biases (Sherman \& Backburn, 1975). Kogan et al. (2010, p. 100) conclude that the benefits can be related to course development, students' sense of influence but they have to be considered in the context of the potential costs, such as "including faculty's loss of confidence and reduced self-image".

\section{Material and methods}

In this section I will give an overview of how the research was conducted for this study. As mentioned, the research targeted teachers in a social work department where the author is employed. The total possible number of respondents was 70. However, the survey response rate was poor with only 25 people and three (30-minute) interviews conducted. This can possibly be attributed to it being a busy time in the term and the subject matter may not have been of interest to the majority of potential respondents. In hindsight it would have been beneficial to have sent out a reminder email-this was not done on this occasion.

The survey was administrated via an online survey (Sunet) tool so as to reach as many respondents as possible. Gathering largescale data enables one to generalise, focus on scores and rating and ensure that the data are representative (Cohen, Manion, \& Morrison, 2007). The benefits of using an internet-based survey include reduced cost and time to distribute, and calculations are carried out automatically. In addition, online surveys are anonymous, accessible and engaging. On the negative side, the online survey risks rapid loss of interest on the part of the respondents. A low response rate (such as $20 \%$ ) is the norm when compared to a paper survey. Reliability can be brought into question given that those who reply are those who are interested in the topic. However, in an effort to address issues of reliability, triangulation is achieved through the use of interviews with some of the survey participants. For validity, the survey was tested through a pilot with a colleague and, as a result, questions were adjusted. The interviews were analysed using a thematic analysis (Braun \& Clarke, 2006) resulting in the creation of three themes. The quantitative data are presented in descriptive format and matched to the three themes. The data were not analysed for gender and experience, although this would have potentially provided an interesting perspective. Approval for the study was sought and given by the head of the department and consent by the respondents was given by their participation in the survey and interviews. The seeking of ethical approval through discussion with the head of department was considered sufficient by the author and the department head. While the respondent numbers were low, they are roughly in line with an expected response rate (Cohen et al., 2007). 


\section{Results and analysis}

The following section is organised via three themes that were created using thematic analysis and that were prominent and recurrent (Braun \& Clarke, 2006) in the empirical data. The themes of engagement and experience, emotional management and strategies for self-development allow the data to be organised in a coherent manner and these are connected to the paper's research questions. The survey and interview data will be discussed together under the relevant themes.

\section{Engagement and experience}

The teachers were asked if they read the student feedback that was connected to their teaching. All the teachers from the survey and all three interviewees reported that they read the feedback, ranging from sometimes to always, with the majority ( $57 \%)$ reporting that they always check student feedback regarding their teaching. With respect to the question regarding whether they sometimes experienced feedback that they considered to be personal in a way which made them uncomfortable, $35 \%$ of the respondents agreed that they had experienced this. On the other hand, $28 \%$ stated that they never experienced anything of that nature. The majority of the respondents $(64 \%)$ felt that the feedback from the students on their teaching could sometimes be helpful.

\section{Emotional management}

Relative to experiencing and managing negative feedback, $85 \%$ of the respondents stated that they speak to colleagues in an informal capacity. By negative feedback, the following examples given by one of the respondents illustrate the type of thing which teachers have read: " $x$ doesn't know how to talk or relate to students" or " $x$ never looks for our opinion, just reads from the slides". Another respondent commented that they "fear looking at the evaluations" because of the expected impact it will have on their emotional well-being. The remaining respondents spoke to either a line manager or family member about it. In contrast, when it came to managing positive feedback, only $42 \%$ would tell a colleague about it, while $21 \%$ would think about it but not tell anyone about it. Significantly, none of the respondents on the survey and interviews answered that they would keep negative feedback to themselves. When asked for an overall reflection on the emotional impact SETs have on them, a total of $21 \%$ stated that they agreed or strongly agreed, with the statement.

\section{Strategies for self-development}

All interview respondents identified that creating opportunities for dialogue with students was the best way to get feedback on teaching. In their opinion, the teacher has to grow a "tough skin" to be able to deal with negative comments, even if it is from a small minority. One respondent highlighted the "benefits of having a structure" and can include something like a "student representative" to be a channel for feedback. This teacher stated that these ideas were things she had developed over time and on an individual basis. The subjective approach to managing student feedback was also echoed by one interviewee who explained that they also used their own approach to getting feedback on their teaching. In this instance, the teacher explained that they used the theory they were teaching by asking students for feedback and engaging in critical reflection and learning on the lecture experience. The interviewee explained that they were trying to "live the model" so to speak, and were able to apply it to the context of student feedback - the respondent spoke about the values underpinning the method she teaches and, in a personal way, she integrated these values in her teaching practice. All interviewees expressed the importance of trust and an openness to self-development when it came to taking on student feedback but they were also in agreement that SET, anonymous and online, were not practically helpful for this. 


\section{Conclusion and discussion}

This paper sought to answer the following questions:

- Do teachers read and identify with student feedback?

- How do the teachers process the feedback on professional and personal levels?

- What strategies do teachers use for pedagogical self-development?

When combining the interview and survey feedback we can get a picture from the respondents that student feedback is important to them. It is clear from the findings that the respondents firstly read the SET, then some internalised the feedback to help develop their pedagogy and others internalised the feedback in ways which make the experience uncomfortable. The management of that feedback reflects the importance of collegial support and, in some ways, this can be seen as a support for professional development. For a significant majority of the respondents, student feedback on their teaching was seen as something which helped their teaching development. The research also revealed that the freedom exists for individual approaches to engage students regarding feedback on their teaching and these strategies are unique to the individual. This makes a case for the importance of flexibility in creating one's own pedagogical well-being-but this presupposes emotional well-being in the first instance. If an individual has a poor self-image or experiences high stress, it is unlikely that that they will feel competent to use individual strategies. The findings point that a certain percentage of the teachers experience SET as negative and, while they have support from peers, the questions remain about how they go about developing their pedagogical wellbeing. There is also an argument to be made that we need to be better at sharing our examples of good practice so that sharing the positive experiences is seen as important for organisational growth and individual development. In conclusion, having SETs as the only formal means for internal pedagogical development simply does not cut it.

\section{References}

Biggs, J. (1999). Teaching for quality learning at university. Buckingham, UK: SRHE and Open University Press.

Biggs, J. (2003). Aligning teaching and assessment to curriculum objectives. York, UK: Higher Education Academy.

Boring, A. (2015). Gender bias in student evaluations of teachers. Report for EU. Retrieved from https://www.ofce.fr/pdf/dtravail/WP2015-13.pdf

Braga, M., Paccagnella, M., \& Pellizzari, M. (2014). Evaluating students' evaluations of professors. Economics of Education Review, 4(C), 71-88.

Braun, V., \& Clarke, V. (2006). Using thematic analysis in psychology. Qualitative Research in Psychology, 3(2), 77-101.

Budd, R. (2017). Undergraduate orientations towards higher education in Germany and England: Problematizing the notion of "student as customer." Higher Education, 73(1), 23-37.

Cohen, L., Manion, L., \& Morrison, K. (2007). Research methods in education. London, UK: Routledge.

de Lourdes Machado, M., Soares, V., \& Teichler, U. (Eds.). (2017). Challenges and options: The academic profession in Europe. Zurich, Switzerland: Springer.

Hamermesh, D., \& Parker, A. (2003). Beauty in the classroom: Professors' pulchritude and putative pedagogical productivity (NBER Working Paper No. 9853). Retrieved from https://papers.ssrn.com/sol3/ papers.cfm?abstract_id=425589 https://www.nber.org/ papers/w9853.pdf

Heffernan, K. (2005). Social work, new public management and the language of "service user." The British Journal of Social Work, 36(1), 139-147.

Hochschild, A. R. (1983). The managed heart Berkeley, CA: University of California Press.

Hornstein, H. (2017). Student evaluations of teaching are an inadequate assessment tool for evaluating faculty performance. Cogent Education, 4(1), 13-32.

Johnson, M. M., \& Wolfer, T. A. (2001). Methods of evaluating teaching in social work education programs: A national survey. Unpublished raw data

Kogan, L., Schoenfeld-Tacher, R., \& Hellyer, P. (2010). Student evaluations of teaching: perceptions of facility based on gender, position and rank. Teaching in Higher Education, 15(6), 100-123.

Kyriacou, C. (2001). Teacher stress: Directions for future research. Educational Review, 53(3), 27-35.

Power, M. (1999). The audit society: Rituals of verification. Oxford, UK: Oxford University Press.

Quinlan, K. M. (2016). How emotion matters in four key relationships in teaching and learning in higher education. College Teaching, 64(3), 101-111. 
Schutz, P. A., \& Zembylas, M. (Eds.). (2009). Advances in teacher emotion research: The impact on teachers' lives. New York, NY: Springer.

Sebastian, R. J., \& Bristow, D. (2008). Formal or informal? The impact of style of dress and forms of address on business students' perceptions of professors. Journal of Education for Business, 83(4), 196-201.

Sherman, B. R., \& Backburn, R. T. (1975). Personal characteristics and teaching effectiveness of college faculty. Journal of Educational Psychology, 67(2), 241-260.

Soini, T., Pyhältö, K., \& Pietarinen, J. (2010). Pedagogical well-being: Reflecting learning and well-being in teachers' work, Teachers and Teaching: Theory and Practice, 16(6), 735-751.

Sutton, R. E., \& Wheatley, K. F. (2003). Teachers' emotions and teaching: A review of the literature and directions for future research. Educational Psychology Review, 15(4), 327-358.

Teater, B. (2011). Maximizing student learning: A case example of applying teaching and learning theory in social work education. Social Work Education, 30(5), 571-585.

Wolfer, T., \& McNown Johnson, M. (2003). Re-evaluating student evaluation of teaching. Journal of Social Work Education, 39(4), 14-30. 